\title{
A Probe into the Impact of Mass Media on Public Policy
}

\author{
Xu Ling \\ Research Department of Chongqing Business Vocational College, Chongqing, China \\ xuling.cn@gmail.com
}

Keywords: The mass media, Internet, Public policy, Influence

\begin{abstract}
Taking the internet as an example, this dissertation analyzed the influence of mass media on the formulation and implementation of public policy. Compared with the public policy, the mass media play the intermediary and supervisory role and displays strong cohesion for its effect on public policy. In modern society, the anonymous, open, free and initiative internet further broadens the mass media's influence on the public policy. However, it should not be neglected that the mass media could in turn weaken the government authority and even affect the independence and accuracy of the setting of public policy because of our unsound legal system and the indifferent political sense of the public.
\end{abstract}

\section{Introduction}

In recent years, with the development of internet technology, the web has become a platform of our spiritual interaction and reality application. The popularity of web has brought us new interactions, changed the structure and operation of the superstructure and affected the human spiritual interaction.

From the perspective of communication, the web has broken the "Gatekeeper" limit of traditional media, and anyone who has access to internet is able to release information although such a discourse power is constrained to some degree. Consequently, the mass media, such as the internet, have greatly promoted our involvement in public life. Taking the internet as an example, this dissertation has probed into the effect of modern mass media on public policy.

\section{The characteristics of public policy}

The public policy, just as its literal meaning, refers to the policy established for the public. It originates from the willing and interest of most people, not personal character.

However, as the public policy is formulated by few government officials, who are obviously entrusted by the government and perform the policy-making function. Thus, to be accountable to the people becomes one of the general principles for modern democratic constitutions and to serve the public becomes one of the government's basic functions. And they are also the starting point for all government public policies.

Therefore, some political elites are apt to reflect their attitudes and values in policy-making, which will lead to the lack of publicity of public policy. The solution is to establish and improve the opinion-expressing mechanism, the policy-participation mechanism and the public opinion supervision mechanism, to encourage public delegates to join in the policy-making and to keep information communication open.

\section{The role of mass media in public policy}

With the development of information era, we increasingly depend on the information we obtain from the media which have the power of deleting, changing, editing and combining information. Consequently, both the traditional books, newspapers and magazines, TV, and movie and the emerging network medium are becoming another major force affecting the public policy. Compared with other policy subjects, it is the most flexible subject of public policy. 
Firstly, the mass media act as mediator. By transferring and expressing opinions between the public and the government, between interest group and government and between interest groups, the mass media reflect social problems immediately and provide policy-makers more reference information. Conversely, the mass media inform the public the progress of policy-making and offer the government requirements of various social interest groups to achieve more satisfactory effects of the policy.

Secondly, the mass media have strong opinion appealing which is able to mobilize social concern and promote the decision making of government.

Thirdly, the mass media act as the supervisor of public policy. The policy effects, such as whether it complies with the public wish, whether it harms the public interest, will be announced by the mass media.

From above discussion it can be seen that the mass media acts as meditator for various policy subjects and catalyst for policy-making with its strong appealing and supervision power.

\section{How do the mass media influence the public policy?}

Since the late 1990s, it is becoming more common for the democratic public opinion to influence the policy, for example, the issue of peasant workers, the health care reform. When these issues were known and discussed by the public, they became policy issues and then public policies.

The focus event highlights the impact of mass media on public policy -compelling the decision-makers to adjust the agenda immediately by arousing social concern. The concentration of concern focuses help to break the past power balance and the strong public pressure will compel the decision-makers to adjust the policies.

When the network medium, which is public, open, interactive, diverse and instant, came into the public view, the setting logic of public agenda altered. Different from the era of traditional media, when it was easy for the government to control the media and affect the agenda, the netizens of the time of mass media can make the issues they concern be part of the public agenda.

Not only the mass media find the public affairs, but also they promote the socialization of conflicts. The media organizations alter the policy-making drive of government by turning the once private problems into public ones and enlarging the audiences' amount. In addition, they also connect the public and the government policy-making system and thus the public are able to participate the decision-making. The mass media gather the public opinion and affect the government policy-making by transforming the separate and potential social wishes and requirements into clear and central policy requirements. It is due to the interaction between media and public that the strong public pressure can come into being and arouse attention from the authority.

\section{The communicative advantage of internet}

The technology development of computer, which is the most important carrier of network media, is a crucial precondition of the fast advancement of the internet. The two words, computer and communication, have the same root -com. In old English, "communicate" means "to participate". There is no journalism but mass communication for American college students. Here, "to communicate" is closely connected with "to participate and exchange". As a wide, open and efficient medium, the web has become a real mass medium through numerous websites visited by thousands of millions of netizens. The network is able to release information more rapid, economic, visual and efficient than any medium, so it is endowed with the function of expression, participation and supervision.

Firstly, the traditional civil participation in politics is constrained by strict official procedures. In China, the National People's Congress and the Chinese People's Political Consultative Conference are the main channels for civil participation in public policy. The supplementary means include the government letters and visits work, the public hearing, and so on. However, in view of the risk of 
identity revealing, the network medium with its anonymity, openness and freedom is more preferable for civil participation in politics.

Secondly, the access threshold for network is relatively low. With basic computer operational skills, anyone can air their understanding and thoughts about the government affairs, vent their neuroses and unsatisfaction, make comments and put forward suggestions for government actions on a network terminal.

Thirdly, the netizens can download information actively and share information through the consultative platform. This new information freedom gives the netizens great initiative to perform their right to know. The netizens' awareness and comment promotes the openness and fairness of the government and has a profound and far-reaching influence on the formulation, application and execution of the government policy.

For example, the network acted as the loudspeaker and the catalyst in the "Guo Meimei incident" and offered the public more open space for discussing public affairs. Due to the characteristics of internet, the common netizens have the unprecedented discourse right and the public right are not under black box operation any more. For example, research shows that the mining accidents of the 1980s are more serious than that of the present but it wasn't known by the public. Since the middle of 1990s, mining accidents have become one of the public focuses because the extensive reports of the mass media, particularly the network, attracted the public attention.

\section{The limitations of internet}

In spite of their positive effects on public policy, the mass media, including the network, have limitations due to subjective and objective reasons.

Firstly, the mass media, especially the internet, is prone to shock of market economy. In reality, the market has had negative impact on the development of Chinese media. Because of the media industry operation, the resource consumption is compensated by advertising revenue. Thus the communication is also affected by advertising. However, the pursuit of audience rating has brought us utilitarian advertising and programme, and it is more and more difficult to judge authenticity and comprehensiveness of report. For example, The Baidu search engine has been exposed to intervene the search results by paid listing.

Secondly, the unsound legal system of internet hinders the full play of its medium function. Beginning in 1969, the internet was applied only for its military utilization. The large-scale use of internet started in 1990s. Since the invention of the WWW, the development of internet has never been expected. The old traditional journalism rules can not keep up with the development of internet technology and network medium, and the incomplete corresponding internet legislation is exhausted with unstable and unordered news networks of various press units.

Secondly, the political passion and media difference of the public affect the full play of the internet function. The anonymous, open and free internet greatly arouses the public passion of political participation. However, the extreme public opinion is adverse to the advancement of the whole social civilization. For example, the patriotic demonstrations of Chinese mainland aiming at Japan which finally turned into crazy nationalistic violence were provoked by the internet and the public opinion to some extent.

Thirdly, the mass media affect and weaken the government authority, and cause the discord between government and media, which may lead to wrong judgment and selection of social subjects of the social system and bring about hidden troubles for policy making.

Lastly, the mass media influence the independence and correctness of the formulation of public policy. Generally speaking, the independence right of decision is contradictory to the participation right of media. While the decision fairness is the core of administrative legitimacy, the independence of decision-makers determine the degree of closeness between them and the law, and the feedback and evaluation of decision requires a stable environment. The interview and report of media will affect the public judgment; especially the freedom and convenience of network may lead to the public prejudice which will hinders the carrying of public policy. Objective reporting is considered as the 
balance of administrative independence and media report, and how to find this balance in the era of internet remains to be explored.

\section{References}

[1] Shen Lu: The Importance of Mass Media for the Public Policy (Legal System and Society, China 2011).

[2] Zheng Qianyin: Analysis on the Influence of Mass Media on the Public Policy-making (The Fortune Time, China 2011).

[3] Zhang Qingsheng: The Online Public Opinion Promotes the Democratic Decision-making of Public Policy (Internet Communication, China 2010).

[4] Wang Xiuli, Pamela.J.Shoemaker: Winning American Hearts and Minds: Country Characteristics, Public Relations and Mass Media (Journal of International Communication, China 2012).

[5] Zhang Qingsheng: The Online Public Opinion Promotes the Democratic Decision-making of Public Policy (Internet Communication, China 2010).

[6] Verstraen.Hans: The Media and the Transformation of the Public Sphere (European Journal of Communication, U.S. 1996). 